\title{
O UNIVERSO FEMININO COMO CENTRO DE INTERESSE E DE ESTUDO EM DISSERTAÇÕES DE MESTRADO: ANOTAÇÕES DE UMA PESQUISA BIBLIOGRÁFICA
}

\author{
João Guilherme Rodrigues MENDONÇA ${ }^{1}$ \\ Paulo Rennes Marçal RIBEIRO
}

\begin{abstract}
RESUMO: O presente artigo se propõe a analisar produções acadêmicas de mestrado que se utilizaram da mídia escrita em revistas voltadas especificamente ao público feminino, defendidas entre 1992 e 2009. O objetivo da pesquisa foi verificar como pesquisadores que tratam do tema têm contribuído para a compreensão do modo que a mulher é retratada na mídia escrita. O presente artigo se propõe a analisar as produções acadêmicas de mestrado, que se utilizaram da mídia escrita em revistas voltadas especificamente ao público feminino. Também foi possível verificar em número menor, revistas com direcionamento editorial não focado especificamente na mulher, e que aguçou pesquisadores de áreas diferentes a compreenderem e analisar como, e em que condição o público feminino é retratado. As dissertações de mestrado foram escritas por mulheres que falam sobre o sexo feminino a partir de revistas destinadas prioritariamente para esse público, com exceção de uma única dissertação escrita por um pesquisador. Os resultados encontrados nas diferentes produções situam o estudo relativo à mulher nas revistas, retratando-a em sua condição de submissão feminina; culto ao corpo; sexualidade; construindo de modo mais ou menos explicito um ideal de mulher; o comportamento feminino condizente a classe social e ao espaço urbano; ser mãe; ser esposa; sua forma de pensar; sua educação; seu lugar de consumidora; seu lugar no espaço público; seu lugar na religião; atuação no mercado de trabalho; estereótipos a ser seguido e consumido. É possível concluir que as características que fazem parte do universo feminino referem-se à normatização de como ser garotas adolescentes; padrões estéticos; visão de corpo ideal e comportamentos desejáveis nas relações afetivo-sexuais; ideal feminino associado à doçura, meiguice, a gestos contidos e estudados, uma imagem suave e discreta e, sobretudo, à passividade; mulher como responsável pela manutenção do relacionamento afetivo; a mulher sob a ótica da beleza e vaidade, a mulher como aquela que possui vaidades estéticas exacerbadas; construção do novo papel social da mulher mãe, boa esposa; guardiã do lar e da religião; conceberem as mulheres como excelente opção de mercado consumidor; corpo feminino educado, disciplinado e regulado; a mulher dependente de normatização na conquista da feminilidade; a mulher mais erotizada; a mulher de meia-idade com exigências de serem eternamente jovens belas e sadias; a mulher mais jovem com exigências de assemelhar-se à mulher madura; a mulher política; o sujeito feminino com identidade fragmentada, contraditória
\end{abstract}

PALAVRAS-CHAVE: Gênero. Mídia. Sexualidade. Revistas femininas.

\footnotetext{
${ }^{1}$ Doutorando em Educação Escolar. UNESP - Universidade Estadual Paulista. Faculdade de Ciências e Letras Pós-Graduação em Educação Escolar - NUSEX - Núcleo de Estudos da Sexualidade. Araraquara - SP - Brasil. 14.800-901. UNIR - Universidade Federal de Rondônia. Departamento de Educação. Porto Velho - RO - Brasil. 78900-000 - jgrmendonca@bol.com.br

${ }^{2}$ UNESP - Universidade Estadual Paulista. Faculdade de Ciências e Letras - Departamento de Psicologia da Educação - Pós-Graduação em Educação Escolar - NUSEX - Núcleo de Estudos da Sexualidade. Araraquara SP - Brasil. 14.800-901 - paulorennes@terra.com.br
} 


\section{Introdução}

O presente artigo se propõe a analisar dissertações de mestrado defendidas entre 1992 e 2009 que se utilizaram da mídia escrita em revistas voltadas especificamente para o público feminino, tendo como objetivo verificar de que modo a mulher é retratada nessas publicações. Ao longo da revisão destas pesquisas verificamos que em algumas produções as revistas utilizadas pelos pesquisadores não se destinavam especificamente à mulher, contudo, partes destas revistas estavam relacionadas à mulher e à identidade feminina.

Estudos e discussões acerca da identidade da mulher representaram a tônica da maioria das dissertações analisadas, sendo que a compreensão do universo feminino foi obtida a partir da leitura e análise de artigos, editoriais cartas e propagandas, que resultaram um amplo leque de informações que envolveram a jovem adolescente, a mulher madura e a mulher da meiaidade.

Lira (2009), com a dissertação Como se constrói uma mulher: uma análise do discurso nas revistas brasileiras para adolescentes, defendida na $\mathrm{UnB}$, investigou as marcas discursivas de identidade feminina nas revistas destinadas a este público específico - as adolescentes brasileiras: Atrevida, Capricho, Smack!, Todateen, Atrevidinha, Atrevida Fashion, Loveteen e Teen Mania. Reconhece a mídia com o potencial de formação identitária da adolescente, com conseqüentes desdobramentos na constituição das identidades de mulher. Seu trabalho investigativo revela a tônica normativa que a mídia escrita impõe-se ao público a que se destina: garotas adolescentes. Esse interesse por essa etapa evolutiva fundamenta-se na compreensão de que “[...] a jovem que está em processo de re-construção de sua individualidade, deixando as coisas de menina e preparando-se para o mundo de mulher.” (LIRA, 1999, p.13). A mídia focada nas jovens, segue compromissada com a mídia feminina destinada a mulher; a preparação de uma identidade feminina.

Santos (2006) também dedica interesse investigativo para o público jovem feminino com a dissertação Ideais de mulher: estética de corpo e de relações afetivo-sexuais veiculados pela mídia escrita em revistas direcionadas ao público jovem no contexto brasileiro. Procurou compreender os ideais de mulher perpassados pelas revistas Capricho e Todateen. A autora considerou os padrões estéticos; visão de corpo ideal e comportamentos desejáveis nas relações afetivo-sexuais; presentificados nas seções que tratavam especificamente de relacionamentos afetivos e interpessoais. Seu foco na imprensa feminina esteve pautado na compreensão de que esta “[...] de modo geral reproduz padrões de relações de gênero 
dominantes na sociedade; assim sendo, as revistas participa da reprodução construção do ideal de felicidade conjugal do determinado contexto social a que fazem parte.” (SANTOS, 2006, p.39). Nesse sentido ela encontrou como resposta nas revistas Todateen e Capricho a construção de mais de um ideal de mulher e muitas vezes contrastante do que venha ser mulher e feminilidade. A mulher precisa ter relacionamentos duradouros e monogâmicos; precisa valorizar o amor romântico. Um dos modelos de ideal feminino “[...] é associado à doçura, meiguice, a gestos contidos e estudados, uma imagem suave e discreta e, sobretudo, à passividade.” (SANTOS, 2006, p.161) A jovem é levada a conceber a discrição em suas investidas com os rapazes de modo sempre indireto e manipulativo (valoriza-se a heterossexualidade). Há indução a “[...] perpetuação de um padrão em que se responsabiliza a mulher pela manutenção do relacionamento afetivo” (SANTOS, 2006, p.164). Contraditoriamente outro ideal de mulher encontrado é aquele em que a mulher é percebida com maior ação, com mais expressão de sentimentos, idéias, assertividade na sexualidade e valorização da singularidade.

Carvalho (2006) em sua dissertação A construção da identidade feminina em Veja, lança seu olhar para a mulher noticiada na revista Veja, procurando compreender como essa mídia constrói a identidade feminina. A autora confirma que a identidade feminina desta revista revela prioritariamente, a mulher sob a ótica da beleza e vaidade, a mulher como aquela que possui vaidades estéticas exacerbadas. Veja, mesmo quando produz notícias cujo foco central não é a preocupação feminina como a aparência física, utiliza recursos lingüísticos para ressaltar aspectos que giram em torno do tema moda ou beleza, minimizando os que não estão diretamente ligados a ele. Por outro lado, de modo minimalista, raramente ou quase nunca mostra a mulher no seu campo de atuação profissional.

Valorizar e reconhecer a mulher a partir da dimensão sobre moda e beleza é de fato recorrente não só nas proposições investigativas das dissertações, como também na maioria dos capítulos dessas produções stricto sensu destinados a revisões históricas relacionadas à mídia escrita em revista destinado ao público feminino. Nessa mesma abordagem, Schmitz (2007) com a dissertação Mulher na moda: recepção e identidade feminina nos editoriais de moda da revista Elle, investigou o fenômeno de midiatização da moda nessa revista. A autora se propõe a compreender o fenômeno de midiatização da moda em dois eixos: no produto editorial de moda Elle, examinando as propostas de feminilidade ali constituídas na relação com a moda. Na recepção destes conteúdos utilizou-se de entrevista com as leitoras para apreender os usos, sentidos e apropriações realizados por elas e as mediações da identidade feminina, das competências de moda e de revista no consumo. Para tanto faz opção de 
analisar a partir dos estudos de gênero, escolhendo a identidade feminina. A autora surpreende com a revelação de que as mulheres da pesquisa não são “vítimas de moda”, ao contrário “[...] imprimem seu gosto e seus valores nas apropriações e nos usos que fazem da moda dos editoriais de Elle.” (SCHMITZ, 2007, p.309). A pesquisa revela que é possível perceber a ação da mídia na constituição do sujeito feminino, sobretudo ao divulgar referenciais de modelos do feminino vinculado a moda, mas que "[...] as mulheres habituaram-se a consumir desde a infância.” (SCHMITZ, 2007, p.312).

Inegavelmente, por outro lado, a mídia cultua uma corporeidade feminina, em que a leitora de revista feminina nem sempre corresponde ao modelo veiculado nas propagandas, capas de revistas, fotos ilustrativa de artigos e textos sobre a mulher. Andrade (2002) analisou essa problematização do corpo feminino produzido e/ou veiculado em revistas voltadas para o público feminino na dissertação Uma boa forma de ser feliz: representação de corpo feminino na revista Boa Forma. A autora procurou compreender como o corpo feminino aparece representado na mídia, compreendendo que a mídia educa disciplina e regula os corpos. Utilizando-se da revista Boa Forma, através de um programa de dieta alimentar e exercícios físicos, denominado Desafios dos Verão, constata que há uma busca incessante de si mesma para as mulheres, ao mesmo tempo em que se evidencia a provisoriedade das identidades e a flexibilidade do corpo. Beleza e saúde são com freqüência confundida. “[...] a obsessão pelo corpo magro, malhado e saudável continua ativa e atual” (ANDRADE, 2002, p.123).

Além da moda, a sexualidade representa um modo de configurar a identidade esperada pelas revistas destinadas ao público feminino. Hollenbach (2005) em sua dissertação Sexualidade em revista: as posições de sujeito em Nova e TPM buscou retirar dos textos das revistas Nova e TPM (Trip para Mulheres) os diferentes enunciados sobre a sexualidade, tentando entender o que se configuraria hoje como uma forma "normal" de vivenciar a sexualidade, bem como as possibilidades de resistência em relação a essa proposta de normalidade, em uma construção de uma determinada feminilidade. A autora identifica diferenças significativa entre as duas revistas, Nova e TPM: "Nova vincula o sexo ao amor e transforma o relacionamento afetivo e sexual numa condição sine qua non para tão almejada felicidade.” (HOLLENBACH, 2005, p.155). Para a revista Nova, o sexo é o principal vínculo entre homem e mulher, e conquistar e manter um homem representa o maior objetivo da mulher. A infidelidade é um tabu e a homossexualidade combatida. Já na TPM, encontramos diferenças significativas em relação à Nova. O sexo representa só mais um aspecto de vida que não é necessariamente o principal. “Diferentemente do que acontece nos vínculos baseados nos anos românticos, nesse tipo de relação a exclusividade sexual só é fundamental 
se os parceiros assim o definirem” (HOLLENBACH, 2005, p.159). Na revista TPM o relacionamento entre homem e mulher não se baseia no sexo e a revista naturaliza sexos extraconjugais e a homossexualidade. O relacionamento amoroso não é uma condição para a felicidade: "Nem o corpo, nem a forma de vivenciar a sexualidade, no entanto, definem a identidade da mulher imaginada pela TPM, que é o resultado das escolhas que faz.” (HOLLENBACH, 2005, p.166). A autora revela ainda que sua pesquisa dectetou que a norma se deslocou do "como" ou de "o que” fazer no âmbito sexual para o próprio fazer.

Rocha (2007), na dissertação Jornalismo em primeira pessoa: a construção de sentidos das narradoras da revista TPM, utilizando-se também da revista TPM buscou confrontar a proposta desta revista de uma ruptura aos manuais que ensinam como ser mulher e reforçam estereótipos historicamente construídos. Com a análise das produções, os discursos das narradoras da revista falam de si mesmas. A autora utilizou-se dos textos em que as narradoras apresentam-se como tema de referência aos assuntos narrados, com a intenção de compreender que imagem de mulher as narradoras auto-referentes da revista TPM constroem sobre si mesmas e que lugares de fala assumem em seu discurso. A autora revela que nessa revista a objetividade esta sempre presente. As inspirações das narradoras não são exteriores a elas, ao contrário, “[...] personagens assumidas nos textos, as narradoras ocupam diferentes lugares de fala para construir o espaço de significação do que anunciam.” (ROCHA, 2007, p.124). Mas a revista revela que há um tensionamento entre duas formações discursivas encontradas: a "Ser mulherzinha" que representa a idéia de mulher multifuncional e naturalizando a construção de gênero feminino como sensível maternal, etc. E a forma discursiva de "Ser fora do padrão" está compromissada com a idéia de desconstrução de muitas características atribuídas culturalmente ao gênero feminino. Esse tensionamento não se revelou em oposição, visto que tanto uma forma discursiva como outra determinou, cada um ao seu modo, a promoção de um necessário padrão a ser seguido. A autora explica que “[...] embora a revista produza discursos que atualizam padrões e estereótipos, e outros que propõem rupturas, destaco que todas convergem para a idéia de que é preciso seguir determinadas regras para exercer a feminilidade.” (ROCHA, 2007, p.129). Todavia, a autora revela ainda que a revista TPM faça jus à compreensão de ser uma revista de ruptura em relação às convenções históricas demarcadas pelas demais revistas femininas. E no outro lado do contínuo, a revista se revela contrária a uma ruptura, mas propunha atualizar padrões consolidados ao agir de modo imperativo dizendo como a mulher deve ser. Desse modo reafirmava a imprensa feminina à moda antiga. 
Retomando a identidade feminina a partir da revista Nova, Guimarães (2006) com a dissertação Nova: 30 anos da mulher de 30, elege como problema central depreender qual o simulacro de mulher construído por essa mídia, com o objetivo de saber se era o edifício da mulher emancipada e de costumes liberados, ou, ao contrário, se a revista tratava da manutenção dos valores e da reificação feminina, a partir das leitoras na faixa etária de 30 anos, em um momento que a revista também completava 30 anos de publicação. A autora certifica que Nova não significa "o estatuto da mudança no universo das revistas femininas" (GUIMARÃES, 2006, p.108), pois há cristalização de valores. Constata, porém, que sob arranjos diferentes, a revista Nova destaca a presença feminina cada vez mais erotizada, e na medida em que são adotados os simulacros veiculados por essa mídia, surgem os sujeitos idealizados dessa construção de identidade feminina.

A revista Nova surgiu para competir o mercado editorial com a revista Cláudia. Na pesquisa A cultura 'psi' das revistas femininas (1970/90): gênero, subjetividade e psicologização (BORGES, 1998) há uma outra perspectiva de análise da identidade feminina. Essa autora procurou captar os processos psicológicos subjetivos do movimento de modernização, a partir de uma pesquisa em artigos recolhidos nestas revistas, com o intuito de verificar as transformações relativas a valores ético-morais, além da percepção de como os discursos das psicologias e da psicanálise entram no campo constituído por essa mídia. Verificou-se o interesse de analisar as orientações relativas ao comportamento feminino, servindo de guia norteador na resolução dos conflitos pessoais, sexuais e da crise da identidade feminina.

Já Resende (2008), em sua produção Mudanças na subjetividade feminina: o papel do discurso publicitário na construção da identidade da mulher de meia-idade, discute o papel da propaganda na construção discursiva da identidade da mulher de meia-idade ao longo de cinco décadas, tendo como referencial a revista Cláudia, por considerá-la uma revista identificada como uma publicação de alta circulação destinada à mulher de classe média, branca, brasileira. A autora analisa a representação visual e verbal da mulher de meia-idade nas propagandas veiculadas na revista, e encontra mudanças que seguem duas direções. Há a constatação de uma abertura que considera gradual a mulher madura em relação ao patriarcado, representado entre diferentes características apontadas pela autora nas diferentes décadas estudada. Como os anúncios destinados a essa mulher são poucos, esses estão associados à presença dela com a família - submissa, impedida para o trabalho, evoluindo para sutis distinções pelo fato de não ser registrada na presença de filhos e marido, e apontando para a possibilidade de trabalho diversificado. A autora apresenta ainda outro 
resultado, que sugere um novo "regime discursivo" à mulher de meia-idade, que enfrenta o desafio de corresponderem às exigências de serem eternamente jovens belas e sadias: “[...] a mulher mais jovem têm seu escopo ampliado e agora passa a ser usado para referência à mulher madura.” (RESENDE, 2008, p.147).

Outro estudo com a revista Cláudia foi o de Ferreira (2006), em sua dissertação As vozes negadas do feminino: uma análise discursiva em cartas de aconselhamento, focando-se nas cartas de aconselhamento da revista. Foram analisados os discursos publicados em edições das décadas de $70,80,90$, e da metade da $1^{\text {a }}$ década do século XXI, para verificar as diferentes vozes que escrevem para apreender a realidade do feminino. A autora optou pelas cartas por compreender que as mesmas possibilitam apreender, sob uma perspectiva discursiva de análise, como os processos de identificação e produção de sentidos se instituem nos discursos sobre/para a mulher. "Na medida em que os discursos se atualizam ao longo das décadas, pode-se perceber que a 'naturalização' da imagem do feminino ainda é uma realidade.” (FERREIRA, 2006, p.15). O resultado apresenta um processo de identificação do sujeito feminino; da mulher nos papéis sociais ocupados em cinco grandes perfis de enunciadores cujos pontos de vista puderam ser recuperados através das afirmativas subjacentes aos enunciados negativos. São eles os enunciadores tradicionalistas, autônomo, subjugado, impositivo e psicanalisado. A mulher esposa em relação ao parceiro o perfil revelou-se tradicionalista, todavia, a mulher apresenta uma autonomia maior no relacionamento. O perfil subjugado esteve representado na mulher mãe, namorada e em relação a sua auto-imagem; o perfil impositivo esteve presente com a as nuanças diferenciadas em todos os papéis de mulher. Configurando o perfil psicanalisado e em menor número, está a mulher que busca responder sobre si em relação ao outro em diferentes lugares.

Outra pesquisa com a revista Cláudia (agora comparada com a revista Ana Maria a partir das classes a que se destinam) foi feita mais recentemente por Bauchwitz (2009) em sua dissertação $O$ popular e o não-popular na imprensa feminina: aproximações e dispersões no estilo e no discurso das revistas Ana Maria e Cláudia. Essa autora pesquisou semelhanças e diferenças entre estas revistas que se destinam ao público feminino de classe $\mathrm{C}$ e de classe A, respectivamente. Estabeleceu o período de fevereiro a maio de 2007, e analisou oito exemplares de Ana Maria e quatro de Cláudia. A pesquisa revelou que os interesses das leitoras das revistas Ana Maria e Cláudia são semelhantes, independente da classe social da mulher. Os temas recorrentes são: sexualidade, beleza, moda, casamento e educação dos filhos. Mantém também a materialização das idéias dominantes sobre o papel da mulher na sociedade. “A heterogeneidade nas revistas em análise é constitutiva, por meio de vozes que 
reforçam o papel da mulher na sociedade, de mãe, boa esposa, sempre linda e magra. Vozes que povoam o universo feminino e que se manifestam nas duas revistas.” (BAUCHWITZ, 2009, p.119).

Uma modalidade diferente de pesquisa em mestrado até aqui abordado focalizou a investigação de revistas segmentada por gênero. Casali (2006), na dissertação Revistas: configuração do relacionamento entre homem e mulher como estratégia de segmentação do público, tratou do tema relacionamento entre homem e mulher a partir das revistas Nova e Malu e das masculinas Vip e PHT. A autora se propôs a investigar o “[...] espaço de mediação produzida pela revista enquanto produto midiático e cultural, para veicular determinados conceitos, valores e condutas socialmente “corretos” no que concerne ao relacionamento entre o homem e mulher.” (CASALI, 2006, p.20). A análise dos textos se ateve às abordagens sobre o discurso entre homem e mulher nas revistas que explorassem sobre namoro, casamento, conquista, separação, sexo, etc. A pesquisa revelou que são semelhantes às estratégias discursivas e configurações expressivas próximas de homem e mulher nas revistas masculinas. Nas revistas femininas, ao contrário das masculinas, há diferença em relação à classe sócio-econômica e/ou grau de instrução a quem se dirige; como também nas configurações expressivas e nas estratégias discursivas empregadas.

Outro corolário de pesquisa relacionado à imprensa feminina esteve focado nesse tipo de mídia escrita relacionado ao público feminino com os valores a moda antiga; entre eles destaco as dissertações de Avila (2007), Nogueira (2008), Ursini (2000), Bassanezi (1992) e Sestini (2008).

\section{Análise e conclusões}

Destacou-se no cenário das produções stricto-sensu em mestrado, dezoito dissertações que tinham como foco de interesse a mídia escrita em revistas direcionadas especificamente ao público feminino; mas também outras revistas como Veja em Carvalho (2006), Boa Forma em Andrade (2002) e Família Cristã em Sestini (2008). Essas revistas não têm sua editoração voltada exclusivamente a um segmento como a mulher; mas mesmo assim representou objeto de análise e atenção dos pesquisadores com temas em suas publicações voltadas para o público feminino.

Destas produções acadêmicas a de Carvalho (2006) e Andrade (2002), transitou em um campo comum: a construção da identidade da mulher em relação à compreensão da estética, aparência física, beleza. Carvalho (2006) destaca a limitação da referência nessa construção 
da identidade feminina ao referir-se a atuação da mulher no mercado de trabalho. Sestini (2008) por outro lado retrata a mulher em uma identidade identificada com a família (esposa e mãe), ao lar e católica conforme a proposição editorial dessa revista (Família Cristã) que vinculado aos princípios cristãos não poderia afastar-se ideologicamente. Todavia, um ideal novo no contexto da época se evidencia que é a ampliação dessa mulher esposa e mãe no espaço público, que terá como função precípua ser a guardiã do lar e da religião diante da ameaça do expansionismo do comunismo ateu. Uma mulher política.

Destas dezoito dissertações encontramos os seguintes dados quantitativos referentes aos cursos: A maioria dos cursos estão ligados a área de Comunicação (Comunicação Social, Comunicação e informação, Comunicação, Ciência da Comunicação, Comunicação e Semiótica), totalizando oito dissertações. A área de História (História, História Social), corresponde a quatro dissertações. Em seguida com um total de três dissertações vem a área de Lingüística. Encontramos com uma dissertação as seguintes áreas: Psicologia; Antropologia Social e Educação.

Os cursos que mais se destacam em produção de dissertação relativa ao tema da mídia destinado ao público feminino estão os de Comunicação, Lingüística e História.

As principais instituições de Ensino Superior com produção em dissertação de mestrado relativo a revistas femininas são: USP; UFPE; UNB; UERJ; UNISINOS; PUC SP; UNICAMP.

No contexto destas dezoito produções acadêmicas de dissertação de mestrado, destacamos em relação aos autores dessas obras, que somente uma dessas pesquisas foi escrita por um mestrando homem: Joaquim Luiz Nogueira (2008), com a dissertação em Comunicação e Semiótica intitulada A construção do corpo feminino na revista O Cruzeiro. Este autor utilizou-se das capas da revista O Cruzeiro para compreender a valorização na construção do corpo feminino entre 1928 a 1940. Encontramos uma mulher brasileira constituída de traços da Europa e do EUA, em um movimento de modernização que o país estava vivendo.

Duas produções acadêmicas foram destinadas à compreensão do feminino estabelecido na mídia impressa por revistas destinadas ao público feminino jovem: Lira (2009), com a dissertação Como se constrói uma mulher: uma análise do discurso nas revistas brasileiras para adolescentes e Santos (2006) com a dissertação Ideais de mulher: estética de corpo e de relações afetivo-sexuais veiculados pela mídia escrita em revistas direcionadas ao público jovem no contexto brasileiro. Ambas revelam interesse direto com a construção da identidade feminina da jovem através de uma aproximação com o que se propaga e preconiza através da 
mídia feminina destinada a mulher. Santos (2006) amplia a discussão ao revelar a diversidade e a contrastante dessa idealização do feminino.

As outras dissertações transitaram por caminhos distintos, que de um modo ou de outro, procuram compreender quem é a mulher. Verbos como construir, constituir, imprimir, configurar, verificar, produzir, representar, normatizar, entre outros, fizeram parte na configuração dessas pesquisas com o intuito de desvelar a identidade feminina. Essa busca eclética nos métodos e nas escolhas das revistas revelou um foco convergente na compreensão da dimensão feminina sob a ótica da beleza e vaidade. A moda, através do modelo, o estereótipo a ser reproduzido e consumido fornece elementos esclarecedores sobre a identidade feminina que em determinada abordagem compreende a mulher como vítima e de fácil influência e no outro extremo como aquela que determina e sabe o que quer, estabelecendo seu próprio modelo e apropriando dele.

O corpo feminino, em sua singularidade, na diferença do masculino precisa ser cultuado. Essa prática revela-se alienante e libertadora. Alienante, quando se vê aprisionada aos modelos veiculados de formas diversas pelas revistas. A mulher nas diferentes idades se vendo com o compromisso de corresponder a um modelo que se revela na obsessão do corpo magro. Libertadora quando a despeito de um modelo a mulher, da voz ao seu desejo e rompe com os estereótipos construídos.

Além do corpo, as análises das dissertações revelam um padrão que transita sem expressiva mutabilidade que é o modelo tradicional de mulher; constituída em uma naturalização da imagem do feminino através de normas de comportamento e de papéis imutáveis constituído de um modo geral como maternal, esposa e heterossexual. Constatou-se o descaso ou o lugar menor da mulher que trabalha; quando muito uma lenta perspectiva de imersão no campo profissional. Há, a padronização revelada como valor expressado pela família e a submissão da mulher.

Para tanto, parece justificado o interesse dessas pesquisas em se debruçar no fenômeno que retrata a presença e a necessidade de ruptura dos diferentes instrumentos utilizados pela mídia impressa dirigido ao público feminino, quanto aos modos objetivos e sutis de ensinar como ser mulher, além da idéia de que é preciso seguir determinadas regras para exercer a feminilidade. Constataram-se padrões consolidados de determinar como a mulher deve ser e de instituírem discursos sobre e para a mulher. O engessamento de valores esteve embutido na maioria das revistas pesquisadas. O discurso modernizante nem sempre representou mudanças sobre a mulher. Um verdadeiro simulacro parece permear a mídia feminina na sua intenção de dar corpo ao ideal de mulher. 
Foi preciso também se debruçar no sentido de captar a subjetividade da mulher, seu comportamento e valores. O relacionamento entre homem e mulher se fez presente na compreensão da subjetividade feminina.

Do conjunto dessas obras de pesquisa, as produções de Avila (2007), Nogueira (2008), Ursini (2000), Bassanezi (1992) e Sestini (2008), enfocam uma temporalidade mais pretérita em relação à atualidade. Avila (2007) retrata em seus estudos com a revista A Estrella o período de 1899 a 1921; Nogueira (2008) o período de 1928 a 1940 utilizando-se da revista $O$ Cruzeiro; Ursini (2000) a década de 1930 também com a revista O Cruzeiro; Bassanezi (1992) analisa o período de 1945 a 1964 através das revistas O Cruzeiro, como também das revistas Jornal das Moças, Cláudia e Querida e Sestini (2008) que pesquisou de 1962 a 1964 a revista Família Cristã.

O universo feminino foi explorado nas pesquisas por vários caminhos, diferentes estratégias, utilizando-se como fonte as revistas. A mulher foi o centro de interesse e de estudo. A grande maioria das pesquisas direcionou seu foco para a especificidade das revistas produzidas para o público feminino; há uma aproximação com a relação direta que cada pesquisador fará relacionando especificamente a mulher. Também foi possível verificar em um número menor, revistas com um direcionamento editorial não focado na mulher, e que aguçou pesquisadores de áreas diferentes a compreenderem e analisar como, e em que condição o público feminino é retratado. As pesquisas de Carvalho (2006) utilizou-se da revista Veja; Andrade (2002) com a revista Boa Forma e Sestini (2008) com a revista católica, Família Cristã, retratam o empenho dos pesquisadores no firme propósito de compreensão da mulher.

\section{THE FEMININE UNIVERSE AS CENTER OF INTEREST AND STUDY AT MASTER'S DISSERTATIONS: NOTES OF ONE BIBLIOGRAPHIC RESEARCH}

ABSTRACT: The present article purpose to analyze Master's academic productions, that use the written media at magazines that are exclusively dedicated to feminine audience, defended between 1992 and 2009. The target of research was verify how researchers that work with theme have contributed for understanding of way that woman is showed in written media. The present article purpose to analyze Master's academic productions that use the written media at magazines that are exclusively dedicated to feminine public. It was also possible to verify, at minor number, magazines with editorial direction not focused specifically at woman, and that provoked researchers of different areas to understand and analyze how and what conditions the feminine public is portrayed. The Master's dissertations were written for women that talk about the feminine sex from magazines that are preferentially dedicated for 
this kind of public, with the exception of one dissertation written by a man. The found results in different productions locate the study concerning to woman at magazines, portray the woman in her condition of feminine submission; cult to body; sexuality; building in a relatively explicit way, one pattern of woman; the matched feminine behavior with social class and urban space; be mother; be wife; her way of thinking; her education; her place as consumer; her place in the public space; her place at religion; her action in labor market; and stereotypes to follow and consume. It is possible to conclude that characters that be part of feminine universe refer to standardization of how to be teenager girls; aesthetical patterns; vision of ideal body and desirable behaviors in sex-affective relations; feminine pattern associated to sweetness, gentleness, to essayed and restrained gestures, a soft and discrete image, and above all, to passivity; the woman as responsible maintainer of affective relation; the woman under the beauty and vanity view, the woman as the only one who have exaggerative aesthetic vanities; building of new social roll of mother woman, good wife; house and religion guardian; conceive women as excellent option of consume market; regulated, disciplined and educated feminine body; the subordinated woman of a standardization in the femininity conquer; the woman more eroticized; the middle-age woman facing demands of be eternally young, beauty and healthy ones; the youngest woman facing demands of resemble as mature woman; the political woman; the feminine subject with a contradictory and fragmented identity.

KEYWORDS: Gender. Media. Sexuality feminine. Magazines.

\section{REFERÊNCIAS}

ANDRADE, S. dos S. Uma boa forma de ser feliz: representação de corpo feminino na revista boa forma. 2002. Dissertação. (Mestrado em Educação) - Faculdade de Educação, Universidade Federal do Rio Grande do Sul, Porto Alegre, 2002.

AVILA, S. M. A construção da subjetividade feminina na obra literária de Francisca Clotilde, Emília de Freitas e na Revista “A Estrella” (1899- 1921). 2007. Dissertação. (Mestrado em História) - Instituto de Ciências Humanas, Universidade de Brasília, Brasília, 2007.

BASSANEZI, C. S. B. Virando as páginas, revendo as mulheres: relações homem-mulher e revistas femininas (1945-1964). 1992. Dissertação. (Mestrado em História Social) Faculdade de Filosofia, Letras e Ciências Humanas, Universidade de São Paulo, São Paulo, 1992.

BAUCHWITZ, N. V. O popular e o não - popular na imprensa feminina: aproximações e dispersões no estilo e no discurso das revistas Ana Maria e Cláudia. 2009. Dissertação (Mestrado em Comunicação) - Centro de Artes e Comunicação, Universidade Federal de Pernambuco, Recife, 2009.

BORGES, D. T. B. A cultura 'psi' das revistas femininas (1970/90): gênero, subjetividade e psicologização. 1998. Dissertação. (Mestrado em História) - Instituto de Filosofia e Ciências Humanas, Universidade Estadual de Campinas, Campinas, 1998. 
CARVALHO, C. P. de. A construção da identidade feminina em Veja. Dissertação. 2006. (Mestrado em Comunicação Social) - Centro de Artes e Comunicação, Universidade Federal de Pernambuco, Recife, 2006.

CASALI, C. Revistas: configuração do relacionamento entre homem e mulher como estratégia de segmentação do público. 2006. Dissertação. (Mestrado em Ciência da Comunicação) - Universidade do Vale do Rio dos Sinos, São Leopoldo, 2006.

FERREIRA, M. C. As vozes negadas do feminino: uma análise discursiva em cartas de aconselhamento. 2006. Dissertação. (Mestrado em Linguistica) - Escola de Comunicação, Universidade Federal do Rio de janeiro, Rio de Janeiro, 2006.

GUIMARAES, M. P. P. da S. Nova: 30 anos da mulher de 30. 2006. Dissertação. (Mestrado em Comunicação e Semiótica) - Pontifícia Universidade Católica de São Paulo, São Paulo, 2006.

HOLLENBACH, G. B. Sexualidade em revista: as posições de sujeito em Nova e TPM. 2005. Dissertação. (Mestrado em Comunicação e Informação) - Faculdade de Biblioteconomia e Comunicação, Universidade Federal do Rio Grande do Sul, Porto Alegre, 2005.

LIRA, L. C. E. Como se constrói uma mulher: uma análise do discurso nas revistas brasileiras para adolescentes. 2009. Dissertação. (Mestrado em Lingüística) - Instituto de Letras, Universidade de Brasília, Brasília, 2009.

NOGUEIRA, J. L. A construção do corpo feminino na revista O Cruzeiro. 2008. Dissertação. (Mestrado em Comunicação e Semiótica). Pontifícia Universidade Católica de São Paulo, São Paulo, 2008.

RESENDE, M. L. Mudanças na subjetividade feminina: o papel do discurso publicitário na construção da identidade da mulher de meia-idade. 2008. Dissertação. (Mestrado em Linguística) - Instituto de Letras, Universidade do Estado do Rio de Janeiro, Rio de Janeiro, 2008.

ROCHA, P. Jornalismo em primeira pessoa: a construção de sentidos das narradoras da revista TPM. 2007. Dissertação. (Mestrado em Comunicação e Informação) - Faculdade de Biblioteconomia e Comunicação, Universidade Federal do Rio Grande do Sul, Porto Alegre, 2007.

SANTOS, D. B. Ideais de mulher: estética de corpo e de relações afetivo-sexuais veiculados pela mídia escrita em revistas direcionadas ao públíco jovem no contexto brasileiro. 2006. Dissertação. (Mestrado em Psicologia) - Faculdade de Filosofia, Ciências e Letras, Universidade de São Paulo, Ribeirão Preto, 2006.

SESTINI, D. P. R. A “mulher brasileira” em ação: motivações e imperativos para o golpe militar de 1964. 2008. Dissertação. (Mestrado em História Social) - Faculdade de Filosofia, Letras e Ciências Humanas , Universidade de São Paulo, São Paulo, 2008. 
SCHMITZ, D. M. Mulher na moda: recepção e identidade feminina nos editoriais de moda da revista Elle. 2007. Dissertação. (Mestrado em Ciência da Comunicação) - Universidade do Vale do Rio dos Sinos, São Leopoldo, 2007.

URSINI, L. B. A revista O Cruzeiro na virada da década de 1930. 2000. Dissertação. (Mestrado em Antropologia Social) - Instituto de Filosofia e Ciências Humanas, Universidade Estadual de Campinas, Campinas, 2000. 